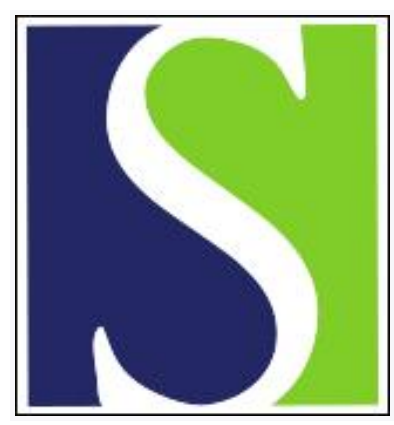

Scand J Work Environ Health 2007;33(2):81-83

https://doi.org/10.5271/sjweh.1110

Issue date: 31 Apr 2007

More systematic reviews needed to improve occupational health

by Verbeek J

Affiliation: Scandinavian Journal of Work, Environment \& Health, Topeliuksenkatu 41 a A, Fl-02500 Helsinki, Finland. jos.verbeek@ttl.fi

Refers to the following text of the Journal: 2007;33(2):85-95

The following articles refer to this text: 2007;33(4):241-243;

2009;35(6):403-413; 2012;38(3):282-290

Key terms: editorial; occupational health; review; systematic review

This article in PubMed: www.ncbi.nlm.nih.gov/pubmed/17460795

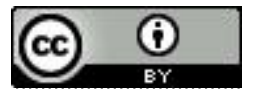




\section{More systematic reviews needed to improve occupational health}

The basic idea in science is that our knowledge progresses slowly and that we build on the results of each others' work. Some have argued that paradigm changes are much more important for scientific progress, but it seems difficult to influence such a paradigm change (1). In the meantime, we can do nothing other than slowly improve our knowledge. That is why reviews are important.

\section{From reviews to systematic reviews}

Reviews have been published for a very long time. The most popular form of review used to be the narrative in which an expert tells what is known on a topic supported by references from the literature. In the 1980s, Mulrow and her co-workers (2) and Oxman \& Guyatt (3) drew attention to the fact that this type of review is highly susceptible to bias and not very informative in practice. Their comments laid the foundation for methodological improvement resulting in systematic reviews. A systematic review is defined as a review of the literature that has been prepared using a systematic approach minimizing biases and random errors documented in a material and methods section (4). Limited searching, selective inclusion of studies, unclear formulated questions, language restriction, or unreliable extraction of data from studies can be sources of such bias.

Methods for combining research results in a more numerical way, as in a meta-analysis, have also been around for over 100 years (5). Meta-analysis is defined as the statistical or mathematical synthesis of study results. The idea is that a meta-analysis too often happens without regard of biases in the primary studies and then results in "mega-silliness". Therefore, the term systematic review is usually preferred over meta-analysis, even though the review can include a meta-analysis. A slightly different development took place in the 1970s in social science in the form of a more systematic approach to meta-analyses (6). The approach relies primarily on summarizing study results quantitatively, for example, in the form of effect sizes. Meta-analyses can be very useful as they can result in a more precise estimate of the effect of an intervention or exposure and can "adjust" for the influence of study size. However, basically, meta-analyses should follow the same principles as systematic reviews.

The enormous progress that has been made in the past 20 years can easily be seen if we compare reviews on similar topics from before 1990 with more recent reviews. For example, the question of whether noise leads to a rise in blood pressure has been reviewed many times in the past, as well as in the present $(7,8)$. In contrast to the oldest review, the most recent one addresses a specific question, specifies the search strategy, has specific inclusion criteria, and uses a clear method for synthesizing the studies. It is a nice example of how the methods used in systematic reviews have developed.

The creation and development of the Cochrane Collaboration in the beginning of the 1990s has also greatly contributed to the improvement of systematic reviews. The Cochrane Collaboration is an international network of researchers and practitioners with the aim of producing systematic reviews about health care intervention and disseminating their results. The rules are presented in a freely available, extensive handbook that can be regarded as a quality handbook for Cochrane systematic reviews (9). An extensive review process ensures that the reviews meet the set methodological and quality standards. It has been repeatedly shown that this process leads to higher quality reviews (10).

Recently the Finnish Institute of Occupational Health started an entity in the Cochrane Collaboration to further systematic reviews on occupational health topics, the Cochrane Occupational Health Field (www.cohf.fi). It has led to a dozen new occupational health reviews being prepared, of which some are already available $(11,12)$. 
Cochrane systematic reviews are published electronically only in the Cochrane Library. The format is such that it does not fit a paper journal because of the extensive summing up of the results of the included studies. With most paper journals an agreement is made allowing the same review to be published.

\section{Is there still room for other reviews?}

The concept of a clinical review or tutorial again differs from that of systematic reviews. The idea is that, an expert in the field describes, also on the basis of a systematic approach to the literature, the general approach to a particular medical problem, such as, for example, back pain, lung cancer, or sore throat. I feel that they have a value of their own for practitioners who need a quick overview. However, they can be highly influenced by the expert's preference for a certain intervention or diagnosis, especially if they are not fully based on evidence from the literature.

\section{Occupational health reviews}

Reviews about work-related or occupational causes of disease have a long history in occupational health journals. However, it seems that the dialectics of progress are at work. We have not yet adopted the recently developed systematic review methodology as much as we should. For example, assessments of the quality of observational studies are not commonplace, and there is no instrument to rate the quality of these studies objectively (13).

Another area of concern is toxicology, a field in which there is a high reliance on expert judgment and no convincing system of synthesizing evidence exists $(14,15)$. It has been shown that reliance on expert opinion alone can differ considerably from inferences based on evidence in the literature $(16,17)$.

To me, it seems that there is still ample room for occupational health reviews especially outside the traditional area of work-related etiology. Currently, many occupational health intervention studies have been performed, and many of them have been collected by the Cochrane Occupational Health Field (18). They are available from the website www.cohf.fi. The prognosis concerning return to work after sickness, the diagnosis of occupational diseases, and the prevalence of exposure are other areas in which studies seem to be begging for review.

\section{Occupational health reviews in the Scandinavian Journal of Work, Environment \& Health}

In this issue, Tompa et al (19) have made one of the first attempts to review the effectiveness of incentives to prevention through insurance and regulations. This is clearly not an easy, although highly relevant, area for review, with unclearly defined outcomes and interventions, few studies, and widely varying methodological quality. These authors did well in coping with all of these challenges in defining concrete inclusion and quality criteria and using best evidence synthesis. For me, it was a surprise to learn that the introduction of occupational safety and health regulations did not have a clear impact on the level of occupational injuries, but that penalties for violating the law did have an impact. More and higher quality studies are certainly needed to support the findings of this review.

I hope that you will reach the same conclusion that I did. There is still ample room for reviews in the Scandinavian Journal of Work Environment \& Health, both in terms of topics and in terms of methodological quality. We are looking forward to your contributions.

\section{References}

1. Lyons SL. Thomas Kuhn is alive and well: the evolutionary relationships of simple life form—a paradigm under siege? Perspect Biol Med 2002;45(3):359-76.

2. Mulrow CD, Thacker SB, Pugh JA. A proposal for more informative abstracts of review articles. Ann Intern Med 1988;108(4):613-5. 
3. Oxman AD, Guyatt GH. Guidelines for reading literature reviews. CMAJ 1988;138(8):697-703.

4. Chalmers I. Foreword. In: Egger M, Davey Smith G, Altman D, editors. Systematic reviews in health care: meta-analysis in context. 2nd ed. London: BMJ Publishing Group; 2001. p xii-xvii.

5. Egger M, Davey Smith G, O'Rourke K. Rationale, potentials and promise of systematic reviews. In: Egger M, Davey Smith G, Altman D, editors. Systematic reviews in health care: meta-analysis in context. 2nd ed. London: BMJ Publishing Group; 2001. p 3-22.

6. Cooper, H, Hedges L. The handbook of research synthesis. New York (NY): Russell Sage Foundation; 1994.

7. van Dijk FJ. Non-auditory effects of noise in industry, II: a review of the literature. Int Arch Occup Environ Health 1986;58(4):325-32.

8. van Kempen EE, Kruize H, Boshuizen HC, Ameling CB, Staatsen BA, de Hollander AE. The association between noise exposure and blood pressure and ischemic heart disease: a meta-analysis. Environ Health Perspect 2002;110(3):307-17.

9. Cochrane handbook for systematic reviews of interventions 4.2.5. Chichester (UK): John Wiley \& Sons Ltd; 2005.

10. Olsen O, Middleton P, Ezzo J, Gotzsche PC, Hadhazy V, Herxheimer A, et al. Quality of Cochrane reviews: assessment of sample from 1998. BMJ 2001;323(7317):829-32.

11. Marine A, Ruotsalainen J, Serra C, Verbeek J. Preventing occupational stress in healthcare workers. Cochrane Database Syst Rev 2006;(4):CD002892.

12. El Dib RP, Verbeek J, Atallah AN, Andriolo RB, Soares BG. Interventions to promote the wearing of hearing protection. Cochrane Database Syst Rev 2006;(2):CD005234.

13. Mallen C, Peat G, Croft P. Quality assessment of observational studies is not commonplace in systematic reviews. J Clin Epidemiol 2006;59(8):765-9.

14. Guzelian PS, Guzelian CP. Authority-based explanation. Science 2004;303(5663):1468-9.

15. Guzelian PS, Victoroff MS, Halmes NC, James RC, Guzelian CP. Evidence-based toxicology: a comprehensive framework for causation. Hum Exp Toxicol 2005;24(4):161-201.

16. Antman EM, Lau J, Kupelnick B, Mosteller F, Chalmers TC. A comparison of results of meta-analyses of randomized control trials and recommendations of clinical experts: treatments for myocardial infarction. JAMA 1992;268(2):240-8.

17. Schaafsma F, Verbeek JH, Hulshof C, van Dijk FJ. Caution required when relying on a colleague's advice a comparison between professional advice and evidence from the literature. BMC Health Serv Res 2005;5:59.

18. Ruotsalainen JH, Verbeek JH, Salmi JA, Jauhiainen M, Laamanen I, Pasternack I, et al. Evidence on the effectiveness of occupational health interventions. Am J Ind Med 2006;49(10):865-72.

19. Tompa E, Trevithick S, McLeod C. A systematic review of the prevention incentives of insurance and regulatory mechanisms for occupational health and safety. Scand J Work Environ Health 2007;33(2):85-95.

Scandinavian Journal of Work, Environment \& Health Jos Verbeek, Associate Editor 
